\title{
Towards a decision support tool: sensitivity mapping of the French Mediterranean coastal environment (a case study of fishery and lodging)
}

\author{
C. Scheurle, H. Thébault \& C. Duffa \\ LERCM, IRSN, La Seyne-sur-mer, France
}

\begin{abstract}
Coastal management implicates decision making processes in order to meet conflicting interests, to target a sustainable development and to guarantee efficient actions to face man-driven pressures. Therefore, adequate decision support tools are needed. The present study is embedded in a project that has the objective to develop an operational simulation tool particularly adapted to manage a crisis situation provoked by accidental marine pollution on the French Mediterranean coast. So as to deal with such a risk, our study is intended to contribute to the analysis of the coastal vulnerability. The vulnerability depends on the exposure to risk factors often linked to human activities, as well as on the environmental and socio-economic characteristics. It is intended to determine these characteristics, to estimate their "values" and to assess the sensitivity of the coastal environment, while the overall aim is to anticipate possible impacts. As demonstrated in various past cases, e.g. an accidental hydrocarbon release impacts different ecosystem types and the environmental services they deliver and that sustain considerable socio-economic activities, such as fishery and tourism. The sensitivity to such impacts has been evaluated for the French Mediterranean coastal environment and sensitivity indices have been attributed to defined coastal zones. Taking seasonal variations into account, here we present sensitivity maps of two "emblematic" coastal activities that are directly or indirectly linked to seawater quality, fishery and lodging.
\end{abstract}

Keywords: coastal management, evaluation, environmental services, market and non market goods, marine pollution. 


\section{Introduction}

\subsection{Development of a decision support tool within the context of coastal management}

Coastal management addresses the interactions of natural ecosystems and human activities. It implicates decision making processes and conservation strategies trying to balance environmental values and anthropogenic uses. In order to meet conflicting interests, to target a sustainable development and to guarantee efficient actions to face man-driven pressures, adequate decision support tools are needed that facilitate an application of mechanisms, monitoring, protection and alerts.

In order to assist management requests, in particular in the case of accidental marine pollution, the project CLARA 2 ("Calculs Liés Aux Rejets Accidentels en Méditerranée", 2006-2010) aims at providing a specific decision support tool for the French Mediterranean coast. The French National Research Agency ("Agence National de la Recherche", ANR) supports the project within its programme on eco-technologies and sustainable development ("Programme Ecotechnologies et Développement Durable", PRECODD). Twelve partners (a consortium of academic research laboratories, industries, civil services and $\mathrm{SME}$ ) are involved in the project, which is labelled by the French cluster of risk management and vulnerability of the territory ("Pôle Gestion Risque et Vulnérabilité de Territoires").

By developing an operational simulation tool, CLARA 2 has the objective to assist in the diagnosis of an accidental discharge of chemical substances (e.g. hydrocarbons) in the coastal environment. To face such pollution and its consequences the assessment of risks, the modelling and forecasting of pathways of the contaminant and the evolution of its concentration in the air-sea system are needed. Moreover, specifically adapted information on the coastal environment and use is necessary in order determine particularly sensitive zones and to propose recommendations to methods, means and priorities of interventions.

\subsection{Assessment of risk and sensitivity to determine the vulnerability of the coastal environment}

Risk factors are often linked to maritime traffic. Today, about $30 \%$ of the international maritime traffic concerns Mediterranean harbours or are on transit and estimated $50 \%$ of the transported merchandises are supposed to present a risk (Aprin et al. [1]). In the Mediterranean, the sector of maritime shipping develops and port facilities, tonnage and frequency of traffic steadily augment. Transport of hydrocarbons takes an important part. The accidental release of hydrocarbons, or more in general accidental marine pollution, is considered as one of the major risks linked to human activity impacting the coastal environment.

However, the impacts on the coast not only depend on the type of substance generating the pollution and its extension but also on the affected zone itself. It depends on its environmental (physical, dynamical and biological) and socio- 


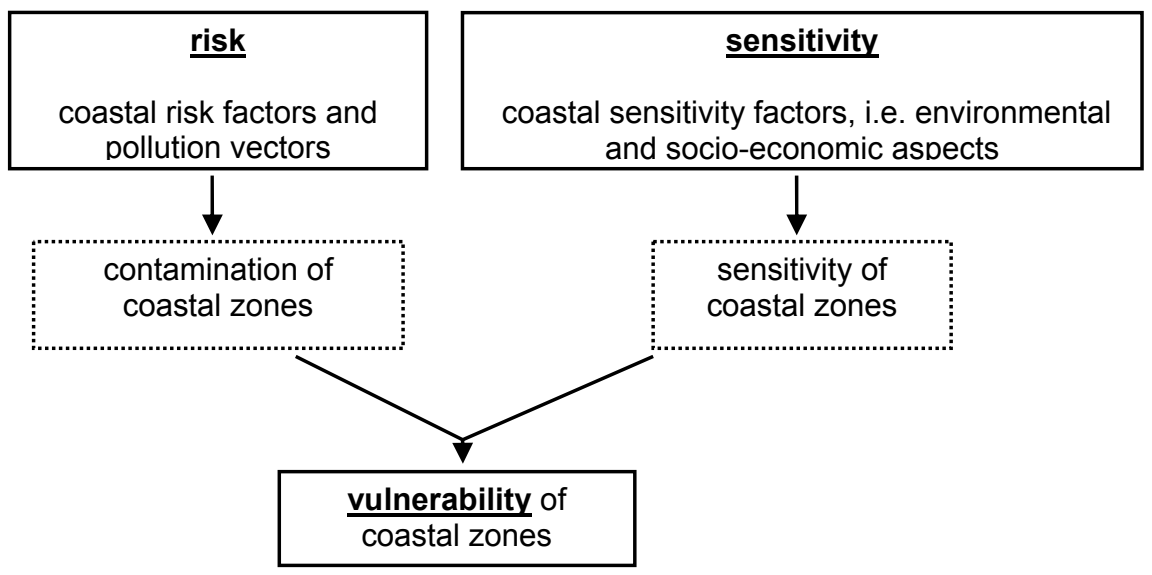

Figure 1: The vulnerability of coastal zones depends on the sensitivity of its environmental and socio-economic factors, as well as on its exposure to risk factors (Duffa et al. [2]; adapted by C. Scheurle).

economic aspects. These aspects characterize a coastal zone, and they indicate and describe its sensitivity (sensitivity factors; Figs. 1 and 2). By evaluating them, sensitivities of the coastal environments to accidental marine pollution are here assessed for the French Mediterranean coast. Subsequently their geographic distribution can be determined which allows the "sensitivity mapping".

Coupling risk and sensitivity assessments then allows determining the coastal zones vulnerability (Fig. 1). Within the context of coastal management the analysis of the vulnerability is important in order to support decisions and to deal with the risks of marine pollution.

\subsection{Approach "services provided by the coastal environment" - placing the present study within its context}

In order to contribute to management and decision making processes as well as conservation strategies, approaches are made to determine "values" of marine and coastal ecosystems. They deliver a wide range of environmental services (cf. e.g. Beaumont et al. [3]) that have important socio-cultural impacts and that sustain considerable economic activities such as fishing and tourism.

Within this context, we aim at estimating values (monetary or non monetary) for the French Mediterranean coast. Taking environmental and socio-economic aspects into account, the undertaken evaluation of quantitative and semiquantitative information is then used to determine respective sensitivities assuming that a higher "value" indicates higher sensitivity.

Three main sensitivity factors have been identified: (a) physical and dynamical, (b) biological and (c) socio-economical. Amongst the factors (a) and (b), we consider physical characteristics such as the coastal geomorphology and the type of sediments as well as the marine biodiversity (e.g. benthic assemblages and rare species). The socio-economic part (c) includes market (e.g. 
fisheries and aquaculture) and non market (e.g. recreational activities) goods and activities. The activities are all linked to a well functioning of the ecosystem and are indirectly or directly depending on seawater quality; the latter supposed being particularly sensitive to impacts caused by marine pollution.

Our inventory of 26 relevant socio-economic activities (criteria) that may be affected in case of marine pollution covers six main sectors: (1) products of the sea (e.g. fisheries and aquaculture), (2) extraction of marine materials (e.g. extraction of salt; therapeutic uses), (3) coastal tourism, sports and recreational activities (e.g. lodging, cruises and yachting, water sports like scuba diving, beaching, recreational fishing), (4) efforts of maintenance, (5) marine research and educational activities, (6) cultural attractiveness and maritime heritage.

Within the goods and services concept of the "Total Economic Value" (TEV; cf. e.g. Ledoux and Turner [4]) this inventory comprises use and non use values. The economic analyses (i.e. monetary estimations) however mainly consider direct uses. Here, we present the case study of two "emblematic" coastal activities, fishery and lodging.

Our analyses position in an ex ante case study, i.e. the evaluation takes socioeconomic activities into account that may potentially be impacted in this particular Mediterranean coastal region. The dimensions of impacts and losses that an accidental release of hydrocarbons may cause have been demonstrated in various past cases (ex post analyses, e.g. Garza-Gil et al. [5], Loureiro et al. [6]).

\subsection{Resume of the present study's main objectives}

The project CLARA 2 aims at developing a support tool for coastal management and decision making in case of accidental marine pollution at the French Mediterranean coast. As part of this project, our work contributes by characterising defined coastal zones in terms of their environmental and socioeconomic aspects.

The present case study focuses on socio-economic aspects, namely the monetary evaluation of two selected activities, fishery (directly linked to seawater quality) and lodging (indirectly linked to seawater quality). This evaluation helps to determine sensitivities which are "translated" into indices. The sensitivity indices are displayed in a geographical context, on sensitivity maps. The maps are supposed to show a relative importance of these exemplary activities within the coastal zones intending to identify "hot spots" of activity and thus action needed.

\section{Elaboration of sensitivity maps of the French Mediterranean coast}

\subsection{Study area and temporal frame}

The study area is situated in the north-western part of the Mediterranean. It embraces the whole French Mediterranean coast which represents ca. 1800 kilometres of coastline. 
From an administrative point of view, the study area is structured in three regions that are subdivided into departments (the latter in brackets; from west to east): Languedoc-Roussillon (Pyrénées-Orientales, Aude, Hérault), ProvenceAlpes-Côte d'Azur (PACA; Gard, Bouches-du-Rhône, Var, Alpes-Maritimes) and Corsica (Haute Corse, Corse Sud). A total number of 189 French municipalities border the Mediterranean Sea of which some are incorporated in agglomerations like Marseille (Bouches-du-Rhône), Toulon (Var) and Nice (Alpes-Maritimes).

In order to elaborate the respective sensitivity maps, the study area has been divided in zones. The division in zones is based on the so-called SDAGE ("Schéma Directeur d'Aménagement et de Gestion des Eaux"), the French outline for the organization of the development and management of water resources. Taking into account main environmental characteristics (e.g. hydrographical dynamics) as well as requirements to management and decision making processes, 32 zones have been distinguished. Seawards the outermost limit of either four miles and/or 50 meters depth has been chosen for the coastal zones.

Tourist activities and their impact mainly during the summer season make a seasonal differentiation necessary (summer: April to September, winter: October to March). The scenario of pollution is limited to a short term event. I.e. the impacting event is supposed to last no longer than days up to, at maximum, a few months.

\subsection{Evaluation method, data collection and treatment}

In order to elaborate sensitivity maps of the coastal zones facing the French Mediterranean and to assess the sensitivity of each zone in case of an accidental marine pollution, detailed information on (environmental and) socio-economic aspects is needed.

Concerning the socio-economic aspects, most recent data accessible on 26 criteria (cf. 1.3) has been collected. Then it has been compiled to match to the 32 coastal zone units (cf. 2.1). After collection of data of socio-economic factors and criteria together with their seasonality, and after an evaluation process, sensitivity indices have been attributed (Fig. 2) to the seaward side, the "marine sector". These indices "translate" the sensitivity criteria on a scale from 1 (less sensitive) to 5 (very sensitive).

The next step will comprise the elaboration of a "global" index, encompassing all socio-economic criteria. Since summer and winter season are regarded separately, two sets of maps result. The produced sensitivity maps will then be compiled in an atlas that will be implemented into the operational simulation tool (cf. Scheurle et al. [7]).

In the context of the present study, we follow this approach for two criteria and focus on two selected socio-economic activities, fishery and lodging. These stand exemplary for activities that are directly or indirectly depending on seawater quality. The catch of seafood, for example, may directly be impacted in case of marine pollution, whereas an onshore tourist activity like the hotel business is rather indirectly dependant on the quality of seawater. 


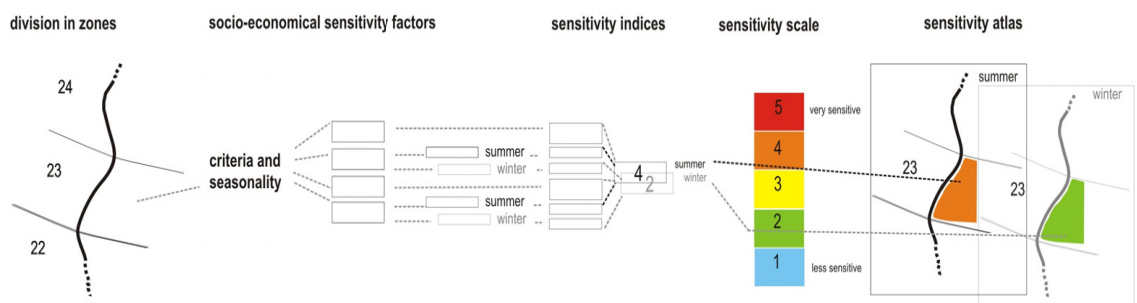

Figure 2: Scheme of the elaboration of a socio-economic sensitivity map. After the division in zones, the main following steps include data collection relative to various criteria representing the sensitivity factors, their evaluation and the attribution of indices, as well as the representation for each of the zones (hypothetic example) (Scheurle et al. [7], adapted by C. Scheurle).

\subsubsection{Data on an activity directly linked to seawater quality - the example of fisheries}

The coastal fishery comprises several different techniques quite specific in each regional context. The intensity of fishery activity within each of the coastal zones, as well as the active fishermen, have been taken into account so as from case to case, average market prices of seafood. Partly data on the revenue were accessible and have been used for the present analysis. No homogenous dataset was available and therefore various sources have been inquired (e.g. IFREMER/SIH Méditerranée [8], OFIMER [9] and pers. comm. "Affaires Maritimes en Méditerranée - DRAM Corse/DDAM/DIR Service économie").

To briefly summarize the evaluation that results in a monetary estimation (in Euros): for Languedoc-Roussillon and PACA the fishery activity per coastal zone has been estimated (month-vessel); the revenues per characteristic fishery type have been determined for each region and redistributed in relation to the fishery activity per coastal zone; presumably $75 \%$ of the estimated revenues are due to summer activity, $25 \%$ concern the winter season. The same percentage has been used for the Corsica region. However, in this case, the revenues per fisherman (anonymous) for each zone have been accounted.

The evaluation results were then used to attribute sensitivity indices on the 1 to 5 scale (1, less sensitive, summer: $<300 \mathrm{~K} €$, winter: $<250 \mathrm{~K} €$; 5 , very sensitive, summer: $>8.000 \mathrm{~K} €$, winter: $>2.500 \mathrm{~K} €$; see above; only summer classification is displayed in Fig. 3) for fishery activity in each of the coastal zones.

\subsubsection{Data on an activity indirectly linked to seawater quality - the example of lodging}

The activity is basically linked to coastal tourism and comprises the hotel business, secondary residences and camping. Primarily data of the French National Institute of Statistics and Economic Studies ("Institut National de la Statistique et des Etudes Economiques", INSEE) have been used, completed by information obtained from local and regional agencies working on the analysis of the tourism sector. 
To briefly summarize the evaluation process: the total numbers of each accommodation type on local (municipality) level have been used to calculate the capacity of accommodation for each coastal zone as well as their occupation (monthly; in percentages). Overnight stays and average expenses per day have been consulted. The summing up of the six summer and winter months results at first for each accommodation type, then for the whole lodging sector, in an evaluation (monetary; in Euros) for each coastal zone.

The resulting values were then used in order to attribute sensitivity indices on the 1 to 5 scale (see above). The lower class (1, less sensitive) integrates values from $<25.000 \mathrm{~K} €$ for the summer season and values $<5.000 \mathrm{~K} €$ for the winter season. The classification in the uppermost class (5, very sensitive) includes summer values of $>250.000 \mathrm{~K} €$ and winter values of $>100.000 \mathrm{~K} €$ (Fig. 4).

\section{Sensitivity mapping of the French Mediterranean coast}

\subsection{Sensitivity maps of two selected socio-economic activities - results}

The (here: monetary) valuation, as described above, allows to attribute sensitivity indices for each coastal zone and subsequently to present them cartographically. The "sensitivity mapping" results for two selected socio-

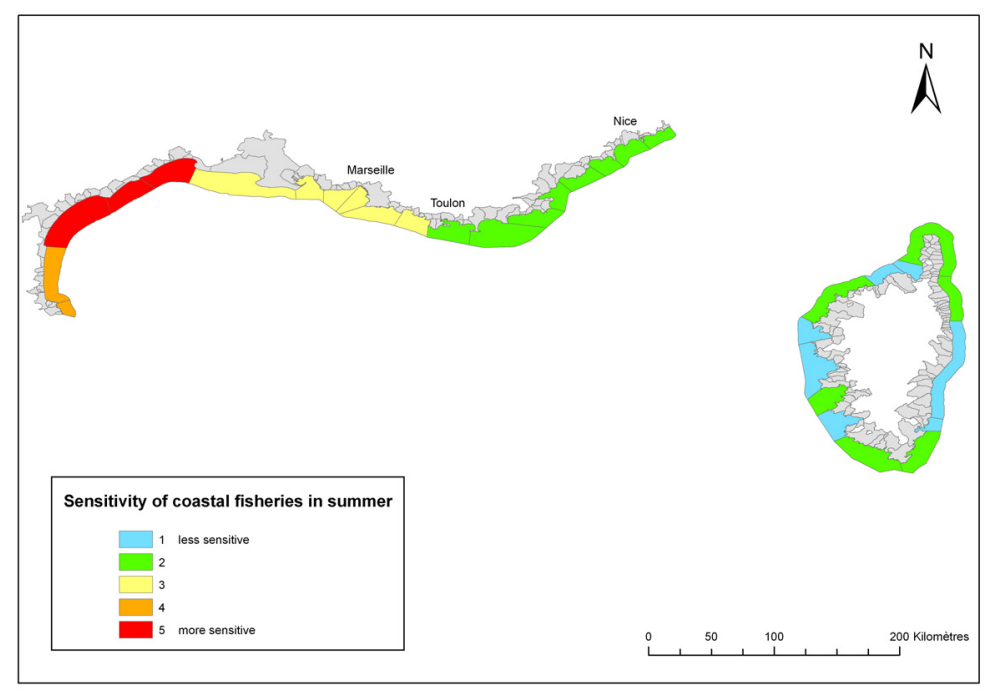

Figure 3: Sensitivity map of an exemplary socio-economic activity that is directly linked to seawater quality - fishery. The map shows the sensitivity indices attributed to fishery activity along the French Mediterranean coast during the summer season for each of the 32 coastal zones. The municipalities belonging to these defined zones are indicated in grey-shading on the landward side. 

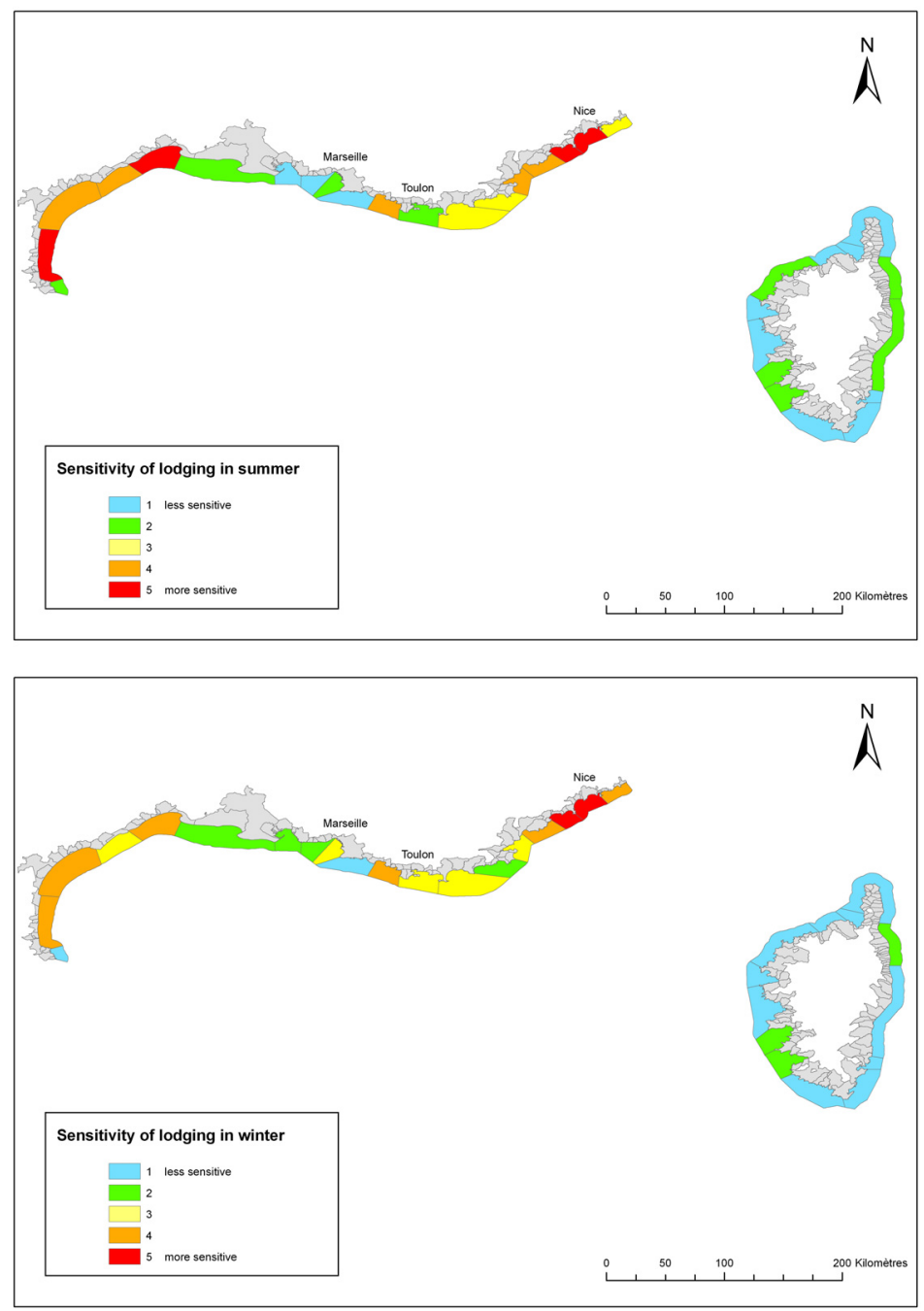

Figure 4: Sensitivity maps of an exemplary socio-economic activity that is indirectly linked to seawater quality - lodging. The maps show the sensitivity indices attributed to accommodation facilities along the French Mediterranean coast during summer (upper map) and winter (lower map) season for each of the 32 coastal zones. The municipalities belonging to these defined zones are indicated in grey shading on the landward side. 
economic activities, fishery and lodging, are presented here. Both activities are linked to marine services and the one is directly linked to seawater quality the other one indirectly.

\subsubsection{Sensitivity map of fishery activity (directly linked to seawater quality)}

All along the French Mediterranean coast, fishery is considered as one of the important activities in terms of socio-economic aspects. Largely more intense fishery activity is to be found in the Languedoc-Roussillon region (cf. 2.1). High sensitivities linked to fishery activity therefore characterize the western French Mediterranean coast (Fig. 3; only summer season displayed). The adjacent eastward coastal zones of the PACA region (cf. 2.1 and Fig. 3) are as well ranked on the upper sensitivity scale, whereas Corsica seems to be comparatively less sensitive in case of an accidental marine pollution.

\subsubsection{Sensitivity map of lodging (indirectly linked to seawater quality)}

In particular due to the tourist activity at the French Mediterranean coast, the values (in Euros) on which the sensitivity indices are based on are relatively high. In summer, Languedoc-Roussillon (cf. 2.1 and Fig. 4) is the region that evidences high sensitivities. Ranked as particularly sensitive are also the coastal zones within the PACA region (cf. 2.1 and Fig. 4) with the agglomeration Nice as "hot spot". In winter, though ranked slightly less sensitive, the same coastal zones than in summer are rather more sensitive in case of an accidental marine pollution (Fig. 4). Then, however, the eastward continuation of the agglomeration Nice becomes relatively more sensitive due to its specific winter tourism.

\subsection{Sensitivity maps of two selected socio-economic activities - discussion}

The presented maps, elaborated on the basis of a monetary evaluation, allow characterizing the French Mediterranean coast with respect to the two selected socio-economic activities. With respect to an activity that is directly (indirectly) linked to seawater quality the relative sensitivities to an accidental marine pollution from one coastal zone to another can be distinguished.

Within this context, and outlining only very briefly here, three aspects need particular consideration. Firstly, the evaluation results are as good as the data available (the datasets were not homogenous i.e. due to the different sources). Secondly, they represent most likely an underestimation. Thirdly, even when displaying the sensitivities in the same manner, the range of values that stands behind the sensitivity scale is different for the two activities. These facts are important for the further use of the maps (cf. below) as well for their interpretation.

\section{Conclusions and perspectives}

The present study is embedded in a project which means to develop a decision support tool, particularly adapted to manage a crisis situation provoked by accidental marine pollution on the French Mediterranean coast. In order to 
contribute to the vulnerability analysis, our work aims at characterizing coastal zones and to assess relevant environmental and socio-economic aspects. An evaluation (monetary and/or non monetary) of these aspects helps to attribute respective sensitivities (sensitivity indices) and to put them in their geographical context.

On the example of selected socio-economic activities, here we present first results of sensitivity mapping of coastal zones along the French Mediterranean coast. To illustrate two socio-economically important sectors, we chose fishery and lodging as exemplary activities.

Fishery is an activity that is directly linked to seawater quality and therefore strongly depending on the well functioning of the marine ecosystems. By estimating monetary values linked to this activity, our study attempts an economic evaluation of one of the goods provided by the marine environment and "directly used and consumed" at a specific geographical scale.

Accommodation capacity and its occupation are linked to seaside tourism and largely profiting from the wide range of environmental assets; they in turn are indirectly depending on the sea and its water quality. By estimating its monetary values, our study therefore tries to partly economically evaluate services provided by the sea that are not directly consumptive.

Both exemplary evaluations differentiate between summer and winter season. On the basis of the seasonal evaluations, sensitivities have been determined for the coastal zones. The resulting indices, hierarchical and used like a cartographic measure, are displayed in their geographical context of the French Mediterranean coast.

In the course of the study, the next steps will envisage to combine the classification results presented and the various other socio-economic sensitivity maps in order to obtain one map representing all different aspects. This will possibly be accompanied by a multi-criteria analysis together with analysis on weighting factors. Given e.g. sanitary aspects, it is to discuss whether activities that are directly linked to seawater/environmental quality should be regarded as "more important" in the present context than indirectly linked activities.

Subsequently, it is planned to gather the socio-economic sensitivity results with the environmental sensitivity maps in a sensitivity atlas (Scheurle et al. [7]) and to integrate them in the development of the decision support tool.

The presented approach is considered as dynamic allowing improvements at any time. Moreover, it is considered as "generic" and therefore supposed to be adaptable for other coastal regions as well as adjustable in terms of its temporal context.

\section{References}

[1] Aprin, L., Lefloch, S., Garreau, P., James, A., Daniel, P., Daumail, V., Sanchez, C., Mouries, M., Casselman, C., Thébault, H., Etasse, C., Roure, J.F., Mercantini, J.M. \& Olier, R., Développement d'un outil informatique opérationnel d'aide à la décision et de modélisation des pollutions en Méditerranée. 16ème Congrès de Maîtrise des Risques et de Sûreté de 
Fonctionnement, Avignon 6-10 October 2008, communication 1Z-8, 8p, 2008.

[2] Duffa, C., Mercat-Rommens, C. \& Thébault, H., Radioecological sensitivity project on the French Mediterranean coastal environment. CIESM, Rapp. Comm. Int. Mer Médit., 38, p. 666, 2007.

[3] Beaumont, N.J., Austen, M.C., Atkins, J.P., Burden, D., Degraer, Dentinho, T.P., Derous, S., Holm, P., Horton, T., van Ierland, E., Marboe, A.H., Starkey, D.J., Townsend, M. \& Zarzycki, T., Identification, definition and quantification of goods and services provided by marine biodiversity: Implications for the ecosystem approach. Marine Pollution Bulletin, 54, pp. 253-265, 2007.

[4] Ledoux, L. \& Turner, R.K., Valuing ocean and coastal resources: a review of practical examples and issues for further action. Ocean \& Coastal Management, 45, pp. 583-616, 2002.

[5] Garza-Gil, M.D., Prada-Blanco, A. \& Vásquez-Rodríguez, M.X., Estimating the short-term economic damages from the Prestige oil spill in the Galician fisheries and tourism. Ecological Economics, 58, pp. 842- 849, 2006.

[6] Loureiro, M.L., Ribas, A., López, E. \& Ojea, E., Estimated costs and admissible claims linked to the Prestige oil spill. Ecological Economics, 59, pp. 48-63, 2006.

[7] Scheurle, C., Thébault, H., Duffa, C. \& Ami, D., Sensitivity Atlas of the French Mediterranean Coast. Özhan, E. (Ed.), Proceedings of the Ninth international Conference on the Mediterranean Coastal Environment, MEDCOAST 09, 10-14 November 2009, Sochi, Russia, MEDCOAST, Middle East Technical University, Ankara, Turkey, 1, pp. 543-553, 2009.

[8] IFREMER, Système d'Informations Halieutiques (IFREMER/SIH) Méditerranée, www.ifremer.fr/sih, 2001 and 2009.

[9] Ministère de l'Agriculture et de la Pêche \& Office National Interprofessionnel des Produits de la Mer et de l'Aquaculture (OFIMER), Bilan annuel de production des pêches et de l'aquaculture, 85p., 2007. 